\title{
Lifestyle changes and breast cancer prognosis: a review
}

\author{
Eliane Kellen · Greet Vansant - Marie-Rose Christiaens • \\ Patrick Neven · Erik Van Limbergen
}

Received: 21 March 2008/Accepted: 21 March 2008/Published online: 4 April 2008

(C) Springer Science+Business Media, LLC. 2008

\begin{abstract}
Objective Because of its high incidence and improving survival, breast cancer is currently the most prevalent cancer in the world. We reviewed the published literature in our search for modifiable factors valuable as an adjuvant health measure to surgery, radio and systemic therapy for breast cancer. Methods We included material which was identified from computerised searches of PubMed (1966 to May, 2007). Published material was restricted to prospective cohort studies and randomised clinical trials. We reviewed the literature concerning the association between physical activity, smoking, weight gain after the diagnosis, diet and prognosis. Results and conclusion We conclude that life style changes following standard breast cancer therapy are highly recommended (although scientific evidence is still lacking for some of inconsistency regarding available data). They include physical activity, weight control, high consumption of fruit and vegetables, and a reduction of dietary fat intake.
\end{abstract}

Keywords Breast cancer $\cdot$ Life style $\cdot$ Prognosis

E. Kellen $(\bowtie) \cdot$ E. Van Limbergen

Universitaire Ziekenhuizen Leuven-LUCK,

Kapucijnenvoer 33, 3000 Leuven, Belgium

e-mail: eliane.kellen@uz.kuleuven.ac.be

G. Vansant

Department of Nutrition, Preventive Medicine,

Catholic University Leuven, Leuven, Belgium

G. Vansant

Department of Nutrition, Preventive Medicine,

University Hospital Gasthuisberg, Leuven, Belgium

M.-R. Christiaens · P. Neven · E. Van Limbergen Multidisciplinary Breast Centre, University Hospitals Leuven, Leuven, Belgium

\section{Introduction}

Breast cancer is by far the most frequent cancer of women. More than half of the cases occur in industrialized countries. Although, the incidence is more modest in Eastern Europe, South America, Southern Africa, and Western Asia, it is still the most common female cancer in these geographic regions. The rates are low in most parts of Africa (with the exception of South Africa) and in most of Asia [1].

Most of the breast cancer risk factors described in the literature are related to a woman's life time exposure to oestrogens: early menarche and late menopause, high total numbers of menstrual cycles and use of oestro-progestons increase the risk; while it is reduced by an early first birth and early menopause [2]. Lactation protects against breast cancer while alcohol increases the risk. The relationship of body fatness with breast cancer risk is equivocal. It probable decreases the risk of premenopause cancer while it increases the risk for postmenopause cancer. Postmenopausal breast cancer seems to be positively associated with abdominal fatness and adult weight gain and negatively with physical activity [3]. Data regarding the role of soy remains conflicting, but adolescent exposure appears to be protective [4]. Positive or negative effects of dietary exposures may be limited to subgroups of women defined by specific genetic characteristics [5]. Breast cancer risk is positively associated with increased smoking during the period between menarche and first childbirth, suggesting that the sensitivity of the female breast to tobacco carcinogens is increased during adolescence and early adulthood [6].

The large variability in the clinical outcome of women with morphological identical breast cancers receiving comparable therapeutic strategies suggest the importance of other life style changes. We therefore reviewed the 
available published literature in our search for modifiable life style factors that may be useful as adjuvant treatment to surgery, radio and systemic therapy for breast cancer.

\section{Search strategy and selection criteria}

Material included in this review was identified from computerised searches of PubMed (1966 to February, 2008) using the medical subject headings $(\mathrm{MeSH})$ terms "breast neoplasm "OR "breast cancer", "AND prognosis" "AND survival" "AND diet" "AND life style" "AND physical activity" "AND smoking" "AND obesity" "AND phytoestrogenes" "AND dietary fat". Only peer-reviewed English language papers were eligible for inclusion. Additional information and studies were obtained by checking the reference lists from retrieved papers. Only prospective breast cancer cohort studies and randomised clinical trials reporting on breast cancer recurrence and survival were included. Currently, few such studies have been designed with the objective to investigate the association between different lifestyle factors and breast cancer prognosis. Most epidemiologic studies were designed to examine aetiology and do therefore not answer whether or not the studied population continued their original lifestyle or altered it after the diagnosis of breast cancer which may bias the results (Table 1).

The Life After Cancer Epidemiology (LACE) Study consists of cohort of 2,321 early stage breast cancer survivors and was designed to investigate how modifiable behavioral risk factors such as diet and physical activity affect quality of life and long-term survival [7].

The Health, Eating, Activity, and Lifestyle (HEAL) Study is a population-based, multicenter prospective cohort study that has enrolled 1,185 breast cancer patients to study the influence of factors such as body weight, physical activity and diet on prognosis [8].

The Shanghai Breast Cancer Survival (SBSS) Study comprises 2,236 Chinese women with breast cancer and collects information on lifestyle related factors and diseaseand treatment related factors [9].

The Women's Healthy Eating and Living (WHEL) Study is a multisite randomized controlled trial of the effectiveness of a high-vegetable, low-fat diet, in reducing additional breast cancer events and early death in women with early-stage invasive breast cancer (within 4 years of diagnosis). The study randomly assigned 3,088 women to an intensive diet intervention or to a comparison group [10].

The Women's Intervention Nutrition (WINS) Study, a randomized, prospective clinical trial of 2,437 assigned women with resected, early-stage breast cancer, receiving conventional therapy, to a dietary intervention group receiving a program of individualized instruction for reducing total fat intake or a dietary control group with minimal dietary counselling. The dietary intervention aims to reduce the percentage of calories with $15 \%$ of habitual intake while maintaining nutritional adequacy [11].

Table 1 Overview of the prospective studies and randomized clinical studies investing the association between life style factors and breast cancer prognosis

\begin{tabular}{|c|c|c|c|}
\hline & Country & Breast cancer & Major exposures of interest \\
\hline \multicolumn{4}{|l|}{ Prospective cohort studies } \\
\hline $\begin{array}{l}\text { Life After Cancer Epidemiology (LACE) } \\
\text { Study [7] }\end{array}$ & US & Stage I \& II invasive & $\begin{array}{l}\text { Diet } \\
\text { Physical activity } \\
\text { Quality of life }\end{array}$ \\
\hline $\begin{array}{l}\text { Health, Eating, and } \\
\text { Lifestyle (HEAL) Study [8] }\end{array}$ & US & $\begin{array}{l}\text { In situ breast carcinoma to stage IIIa breast } \\
\text { carcinoma }\end{array}$ & $\begin{array}{l}\text { Diet } \\
\text { Physical activity } \\
\text { Weight }\end{array}$ \\
\hline $\begin{array}{l}\text { Shanghai Breast Cancer Survival (SBSS) } \\
\text { Study [9] }\end{array}$ & China & Newly diagnosed & $\begin{array}{l}\text { Life-style } \\
\text { Disease- and treatment-related } \\
\quad \text { factors } \\
\text { Quality of life }\end{array}$ \\
\hline \multicolumn{4}{|l|}{ Randomized clinical trials } \\
\hline $\begin{array}{l}\text { Women's Healthy Eating } \\
\text { and Living (WHEL) Study [10] }\end{array}$ & US & Stage I ( $\geq 1 \mathrm{~cm})$, II or IIIA invasive & High-vegetable, low-fat diet \\
\hline $\begin{array}{l}\text { Women's Intervention Nutrition (WINS) } \\
\text { Study [11] }\end{array}$ & US & $\begin{array}{l}\text { Invasive (exclusion for tumour size less than } \\
1 \mathrm{~cm} \text { with negative nodes; tumour size greater } \\
\text { than } 5 \mathrm{~cm} \text { with positive nodes; } 10 \text { or more nodes } \\
\text { positive) }\end{array}$ & Dietary fat reduction \\
\hline
\end{tabular}




\section{Results}

Physical activity

A cohort study of 2,987 women in the Nurses' Health Study, diagnosed with stage I, II or III breast cancer found a protective effect of physical activity on cancer-related mortality. The greatest benefit occurred in women who performed the equivalent of walking 3-5 h per week at an average pace and among women with hormone-responsive tumours [12]. Similar results were found by a cohort study of 4,482 invasive breast cancer patients [13] and for two studies that investigated the relationship between breast cancer mortality and pre-diagnostic physical activity $[14,15]$. Results from the WHEL study indicated that the combination of consuming at least five servings of vegetables-fruits and physical activity (30 min of walking at moderate pace for 6 days a week) is associated with an increase in survival in women with estrogen-positive receptor tumours [16]. However, an Australian cohort of 451 women with breast cancer found no association. Likewise a cohort study in Canada of 603 women with incident breast cancer found no association between physical activity and breast cancer mortality [17].

A trial that randomized sedentary, obese breast cancer patients to a cardiovascular and strength training exercise intervention or to a usual care control demonstrated that exercise is associated with a decrease in insulin levels [18].

\section{Biological mechanism}

The literature remains controversial whether or not in postmenopausal women, increased physical activity is associated with decreased serum concentrations of oestradiol and oestrone [19]. Nonetheless, a randomized clinical trial found that exercise may decrease serum oestrogens levels in previously sedentary, obese postmenopausal women [20].

In premenopausal women, research indicates longer menstrual cycles, and lower progesterone and oestradiol levels in athletes compared with control subjects. A randomized controlled trial concluded that a 12 -week aerobic exercise training intervention did not alter oestrogen metabolism in premenopausal women [21].

High circulating levels of Insulin-Like Growth factor (IGF)-1 may be positively associated with increased risk of breast cancer. The current literature is not conclusive on the relation between increasing physical activity and IGF-1 levels [19]. However, it was demonstrated that IGF-1 is a mediator of estradiol mitogenic effects [22].

\section{Smoking}

A cohort study of 5,056 women in the Nurses' Health Study, diagnosed with breast cancer, found no association between a history of smoking and breast cancer-related mortality or an increased risk of breast cancer recurrence [23]. Similar results were concluded by two other cohort studies [24, 25]. In contrast, a Swedish cohort study concluded that the breast cancer mortality was the lowest in those who had never smoked, the highest in smokers, and somewhere in between in ex-smokers [26].

\section{Biological mechanism}

Nicotine is the main immunosuppressive constituent of cigarette smoke, which inhibits both the innate and adaptive immune responses [27]. Smoking may have an 'antioestrogenic' effect although endogenous oestrogen levels have not been found to differ significantly when comparing current smokers with former smokers or non-smokers [28]. However, it should be noted that cigarette smoking is inversely associated with the risk of endometrial cancer among postmenopausal women, which is another oestrogen dependent tumour [29].

Obesity and weight gain after the diagnosis

The majority of the existing literature indicates a negative relationship between obesity and poor prognosis of breast cancer in both pre- and post-menopausal women [30]. Weight gain after diagnosis has been reported frequently, possibly through increased caloric intake, changes in physical activity and change in host metabolic status [31]. Women who gained weight after diagnosis are found to be at greater risk for breast cancer recurrence and death compared to women with a lower body mass index (BMI) [32].

Analyses from the Nurses' Health Study showed that weight and weight gain after the date of diagnosis were related to higher rates of breast cancer recurrence and mortality. These findings were especially apparent in women who never smoked, among women with earlier stage disease or those who were normal weight before diagnosis [33]. In contrast, a collaborative effort between the LACE study and the WHEL study, did not observe an association between post-diagnosis weight gain and recurrence risk in the first 5-7 years postdiagnosis [34].

If circulating estrogen levels are the linking mechanism between adiposity and breast cancer recurrence, weight loss may no longer have an impact on recurrence or survival in postmenopausal women with estrogen-positve receptors treated with the third generation aromitase inhibitors (exemestane, anastrozole, letrozole). As these drugs suppress estradiol levels in post-menopausal women by $84 \%$ or more [35]. 


\section{Biological mechanism}

Increasing BMI is associated with increased oestradiol levels. Hyperinsulinism has been associated with a poor breast cancer prognosis, possibly mediated by the neuroendocrine hormone leptin that is produced by adipose tissue [28]. Obese postmenopausal breast cancer survivors have increased estrone, estradiol, free estradiol, levels and decreased sex-hormone-binding globulin levels [36]. Furthermore, it has been suggested that obese women with breast cancer may receive reduced doses of adjuvant chemotherapy [37]. Higher BMI has been related to more advanced stages of breast cancer at diagnosis in terms of tumour size [38]. Obesity appears not to interfere with the efficacy of tamoxifen in women with lymph-node negative, oestrogen receptor-positive breast cancer [39].

\section{Phytoestrogenes}

Phytooestrogens are plant compounds that are structurally similar to mammalian oestrogens. They possess oestrogenic and antioestrogenic properties through binding on oestrogen receptors. Some data from in vitro and animal studies suggest that isoflavones, especially genistein, may stimulate the growth of oestrogen-sensitive tumours. Further research is therefore needed to determine effect of soy foods or isoflavones on breast cancer risk in high-risk women and on the survival of breast cancer patients [40]. Although, a Chinese study found no relationship between soy food intake before diagnosis and survival [41], it is not recommended to use soy to reduce menopausal symptoms in breast cancer patients [4].

It has been suggested that phytooestrogenes may influence the effect of tamoxifen, a selective oestrogen receptor modulator, in breast cancer treatment either in a antagonistic or synergistic way [4, 42]. However, a crosssectional study in Asian Americans with breast cancer who were tamoxifen users found no relation between selfreported intake of soy and serum levels of isoflavones [43].

It should be noted that estrogen therapy is contraindicated after the diagnosis of breast cancer [44, 45].

\section{Dietary fat}

In women with oestrogen receptor positive breast cancer, a positive association between treatment failure and high intakes of total fat, saturated fat and polyunsaturated fatty acid has been suggested [46]. The association between dietary fat intake and reduced survival has been confirmed in both postmenopausal and premenopausal breast cancer patients [47-51]. Interim results of the WINS study suggest a benefit of dietary fat reduction on relapse-free survival. Secondary analyses suggested a stronger effect for dietary fat reduction on breast cancer recurrence in women with hormone receptor-negative cancers compared with women whose cancers were hormone receptor positive [52]. In contrast, the Nurses' Health Study did not conclude that a low fat diet after diagnosis leads to a survival advantage [53]. The same conclusion was reached by a prospective study of 213 breast cancer patients in Japan; it should be remarked that Japanese women develop breast cancer at an earlier age and consume relatively small amounts of fat (mean dietary fat intake was about $23 \%$ of calories) [54].

\section{Biological mechanism}

Experimental studies indicate that the polyunsaturated fatty acids, rich in linoleic acid enhance the promotion and progression of mammary cancer, whereas omega-3 fatty acid-containing fish exert a protective effect [55]. Laboratory and animal experimental evidence indicate that dietary fat intake influences breast cancer growth through changes in circulatory hormonal levels, changes in cell membrane structure and function, changes in prostaglandin and cytokine/monokine levels and altered regulatory gene expression [31]. A high-fiber, low fat diet intervention has been shown to be associated with reduced serum bioavaliable oestradiol concentration in women diagnosed with breast cancer [56].

\section{Other dietary macro- and micronutrients}

It has been shown that in post-menopausal women diagnosed with breast cancer, reduced fat and increased fiber, vegetable and fruit intakes improves overall survival [48]. But analyses from the Nurses' Health Study found that adherence to a prudent dietary pattern (characterized by a diet high in fruits, vegetables, whole grains, legumes, poultry and fish) was not associated with breast-cancer mortality but was negatively related to mortality from other causes [57]. The WHEL randomized trial confirmed that adherence to a diet very high in vegetables, fruit and fiber and low in fat does not reduce breast cancer recurrence or mortality [58]. In contrast, high consumption of $\beta$-carotene and vitamin $C$ seems to influence survival [59]. Supplement use of vitamin $\mathrm{C}$ or $\mathrm{E}$ has been suggested to be associated with an decrease in breast cancer recurrence or breast-cancer related death [60]. Women, assigned to the non-intervention group of the WHEL study, with high plasma-carotenoid concentration, had a significantly reduced risk for breast cancer recurrence [61]. Interestingly, analyses of a cohort study of 477 breast cancer patients found that the association between key dietary variables with survival may be U-shaped and not linear. Thus moderate, rather than low, fat intakes are associated 
with optimal survival [62]. A randomized clinical trial of fenretinide (a synthetic retinoid) showed a reduction of second breast cancer, which was more apparent among premenopausal women [63].

No evidence has been found that antioxidant vitamin supplements reduce the toxicity associated with chemotherapy [64]. Some authors even advise against the use of antioxidant supplements during chemotherapy or radiotherapy [65].

High alcohol consumption may be associated with an increase in breast cancer mortality [66].

\section{Biological mechanism}

The cancer-preventive capacities of carotenoids are attributed to their anti-oxidant capacities and their effect on gap junctional communication which play a role in the regulation of cell growth, differentiation and apoptosis [67]. It has been demonstrated that carotenoids influence the proliferative capacity and differentiation of mammary epithelial cells [68]. But the negative relationship between prognosis and increased fruit and vegetable consumption may partly due to the fact that a high fruit and vegetable consumption is merely a marker for low dietary fat intake. An increased estrogen concentration and a change in folate metabolism are mentioned among the mechanisms linking alcohol with breast cancer [69].

\section{Discussion}

Despite the wealth of etiologic studies on breast cancer risk and the growing number of breast cancer survivors, surprising little is known on the association between life style changes made after the diagnosis of breast cancer and the outcome. Currently, only two randomized control trials are studying the relationship between lifestyle related factors and prognosis [10, 11]. Both of them restricted inclusion to early stage breast cancer. While merely three large cohort studies of breast cancer patients are collecting data [7-9].

Based on available literature, a multidisciplinary approach regarding breast cancer is recommended and should include physical activity, body weight control, high consumption of fruit and vegetables, and a reduction of dietary fat intake. Recent results from the WHEL study suggested that a healthy lifestyle that combines high levels of fruit and vegetables consumption with physical activity is associated with an increase in survival [16]. Thus rather than one factor, a combination of lifestyle behaviors may improve breast cancer survival [70]. Besides the beneficial effect on recurrence, a healthy diet and regular exercise has the potential to reduce the risk of co morbidity (such as other cancers, cardiovascular disease, diabetes, etc.) and improving the quality of life (through a reduction of the risk on fatigue and depression) [71]. The American Cancer Society has summarized the best clinical practices related to optimal nutrition and physical activity during treatment and recovery, living after recovery from treatment and living with advanced cancer [72]. An overview of other resources available concerning information and health promotion to cancer survivors is given elsewhere [71]. Although many patients with cancer report healthier lifestyles after diagnosis, these changes might be temporary. Few studies have investigated the most appropriate intervention time (at diagnosis or later), patients' preferences about delivery of interventions or the relative efficacy of different methods (clinic versus home-based, face-to-face counselling, mailed interventions, telephone counselling, etc.) [71]. The FRESH START trial which included newly diagnosed breast or prostate cancer patients found that tailored mailed interventions are more effective in promoting healthful life styles (which included exercise, consumption of fruit and vegetables, overall diet quality, and decreasing intake of fat and saturated fat) than standardized materials [73]. More research is warranted. Unfortunately, although cancer survivors may be susceptible to health promotion, many health care providers may miss opportunities to counsel survivors about healthy behaviours [74]. Nevertheless, health care providers do have an important educational role concerning modifiable causes of cancer. A survey of cancer survivors' beliefs showed that the respondents underestimated the importance of behavioral factors (such as obesity and physical inactivity) known to be related to be with increased cancer risk, while overestimating the importance of stress and environmental pollution [75].

More research is needed before conclusive advice can be given to women with breast cancer. Intervention studies should answer on what lifestyle changes may be used as adjuvant therapy or as a modifier of tumor growth and progression. Future studies on the association between breast cancer prognosis and modifiable factors need to obtain complete clinical, dietary, and lifestyle information at moment of breast cancer diagnosis and this should be updated regularly during follow up. Albeit a challenge in designing, clinical trials are needed to determine the effect of physical activity on the recurrence and mortality of breast cancer [76]. To date, the WINS study is the first randomized trial that suggested that a dietary intervention may reduce breast cancer recurrence [52]. Future studies should investigate whether or not there is a threshold of dietary fat intake at which an increase in tumour recurrence is observed (Table 2). 


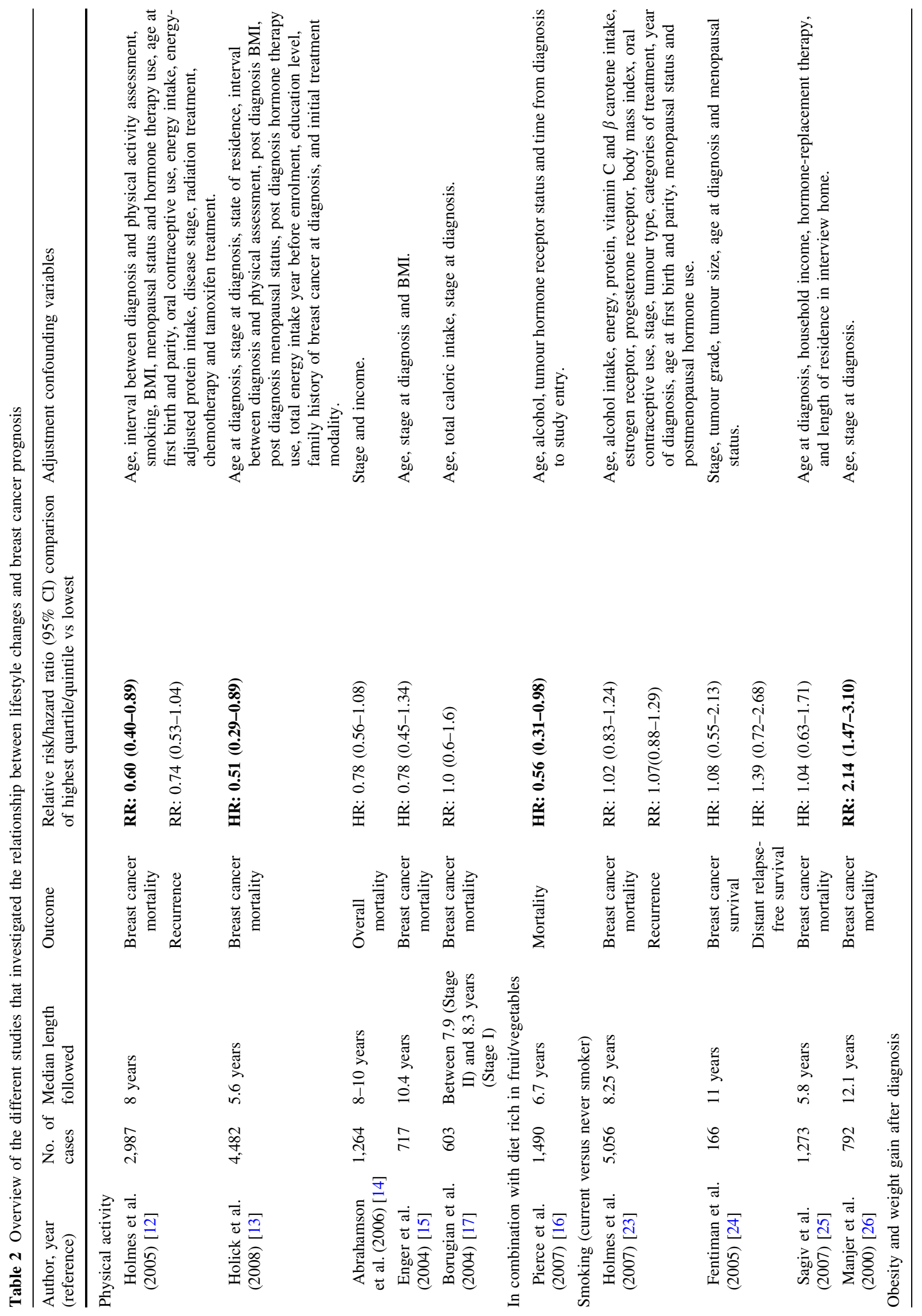




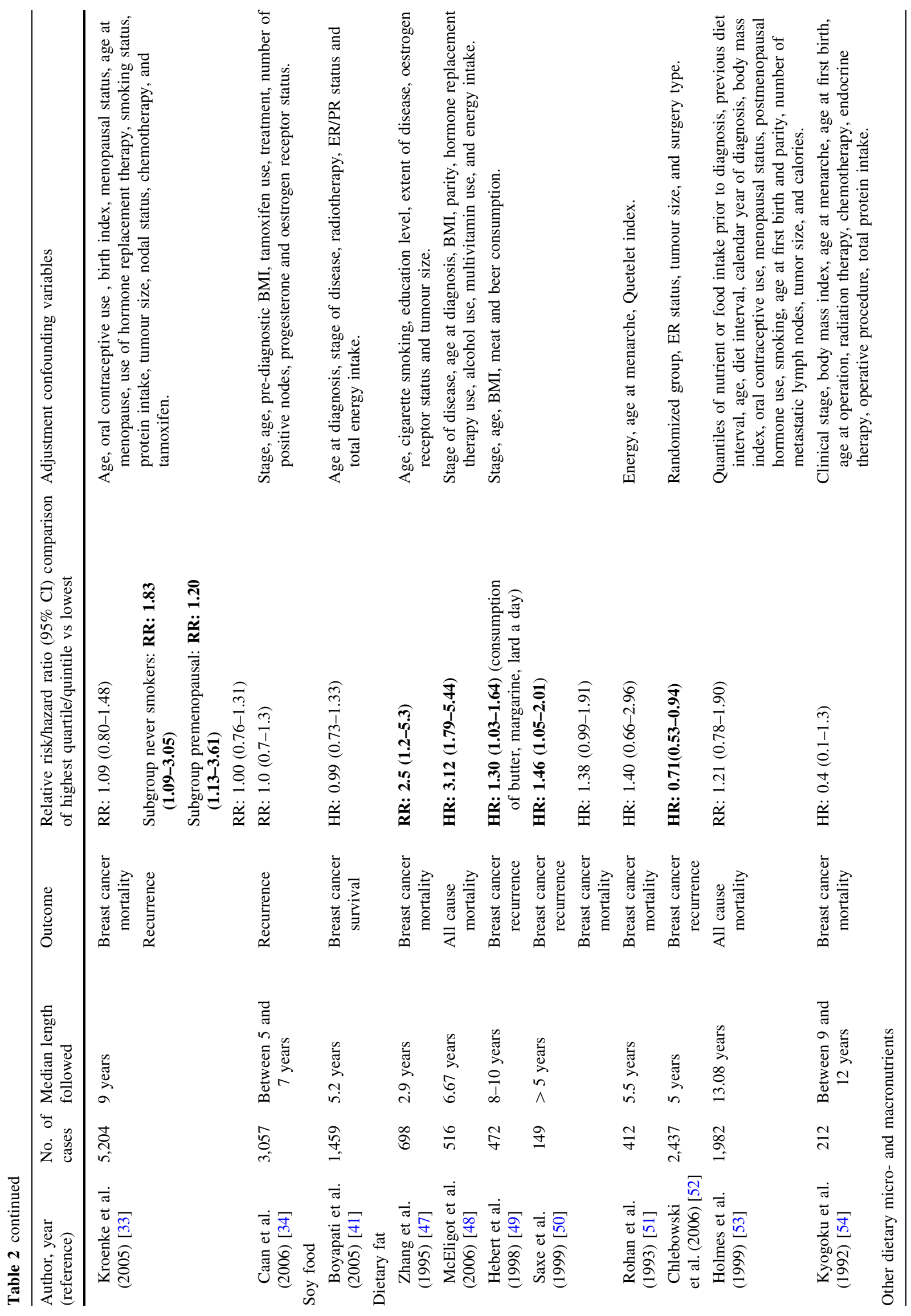




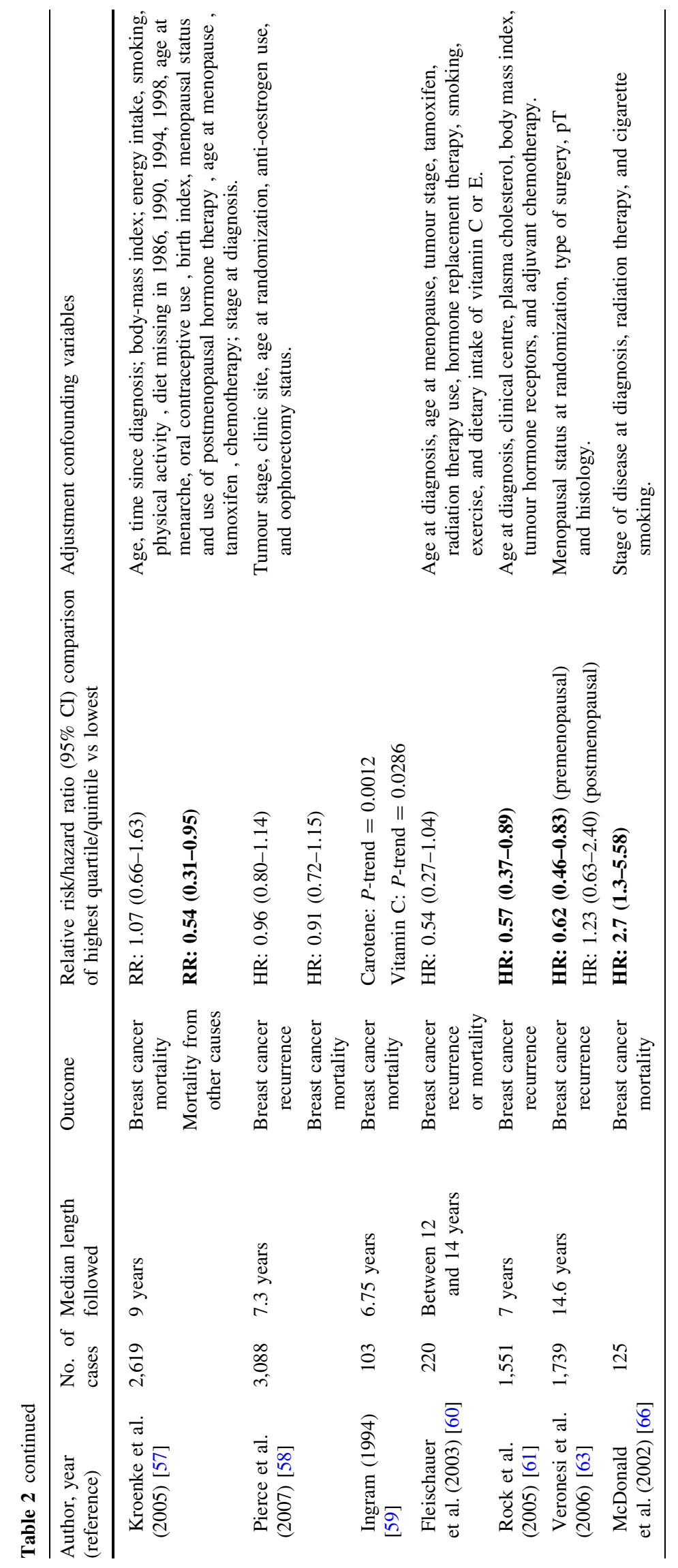




\section{References}

1. Parkin DM, Bray F, Ferlay J, Pisani P (2005) Global cancer statistics, 2002. CA Cancer J Clin 55:74-108

2. Key TJ, Verkasalo PK, Banks E (2001) Epidemiology of breast cancer. Lancet Oncol 2:133-140

3. World Cancer Research Fund/American Institute for Cancer Research (2007) Food, nutrition, physical activity, and the prevention of cancer: a global perspective. AICR, Washington

4. Duffy C, Perez K, Partridge A (2007) Implications of phytoestrogen intake for breast cancer. CA Cancer J Clin 57:260-277

5. Michels KB, Mohllajee AP, Roset-Bahmanyar E, Beehler GP, Moysich KB (2007) Diet and breast cancer: a review of the prospective observational studies. Cancer 109:2712-2749

6. Ha M, Mabuchi K, Sigurdson AJ et al (2007) Smoking cigarettes before first childbirth and risk of breast cancer. Am J Epidemiol 166:55-61

7. Caan B, Sternfeld B, Gunderson E, Coates A, Quesenberry C, Slattery ML (2005) Life After Cancer Epidemiology (LACE) Study: a cohort of early stage breast cancer survivors (United States). Cancer Causes Control 16:545-556

8. Irwin ML, Crumley D, McTiernan A et al (2003) Physical activity levels before and after a diagnosis of breast carcinoma: the Health, Eating, Activity, and Lifestyle (HEAL) study. Cancer 97:1746-1757

9. Lu W, Cui Y, Zheng Y et al (2007) Impact of newly diagnosed breast cancer on quality of life among Chinese women. Breast Cancer Res Treat 102:201-210

10. Pierce JP, Faerber S, Wright FA et al (2002) A randomized trial of the effect of a plant-based dietary pattern on additional breast cancer events and survival: the Women's Healthy Eating and Living (WHEL) Study. Control Clin Trials 23:728-756

11. Chlebowski RT, Blackburn GL, Buzzard IM et al (1993) Adherence to a dietary fat intake reduction program in postmenopausal women receiving therapy for early breast cancer. The Women's Intervention Nutrition Study. J Clin Oncol 11:20722080

12. Holmes MD, Chen WY, Feskanich D, Kroenke CH, Colditz GA (2005) Physical activity and survival after breast cancer diagnosis. JAMA 293:2479-2486

13. Holick CN, Newcomb PA, Trentham-Dietz A et al (2008) Physical activity and survival after diagnosis of invasive breast cancer. Cancer Epidemiol Biomarkers Prev 17:379-386

14. Abrahamson PE, Gammon MD, Lund MJ et al (2006) Recreational physical activity and survival among young women with breast cancer. Cancer 107:1777-1785

15. Enger SM, Bernstein L (2004) Exercise activity, body size and premenopausal breast cancer survival. Br J Cancer 90:2138-2141

16. Pierce JP, Stefanick ML, Flatt SW et al (2007) Greater survival after breast cancer in physically active women with high vegetable-fruit intake regardless of obesity. J Clin Oncol 25: 2345-2351

17. Borugian MJ, Sheps SB, Kim-Sing C et al (2004) Insulin, macronutrient intake, and physical activity: are potential indicators of insulin resistance associated with mortality from breast cancer? Cancer Epidemiol Biomarkers Prev 13:1163-1172

18. Ligibel JA, Campbell N, Partridge A et al (2008) Impact of a mixed strength and endurance exercise intervention on insulin levels in breast cancer survivors. J Clin Oncol 26:907-912

19. Campbell KL, McTiernan A (2007) Exercise and biomarkers for cancer prevention studies. J Nutr 137:161S-169S

20. McTiernan A, Tworoger SS, Rajan KB et al (2004) Effect of exercise on serum androgens in postmenopausal women: a 12-month randomized clinical trial. Cancer Epidemiol Biomarkers Prev 13:1099-1105
21. Campbell KL, Westerlind KC, Harber VJ, Bell GJ, Mackey JR, Courneya KS (2007) Effects of aerobic exercise training on estrogen metabolism in premenopausal women: a randomized controlled trial. Cancer Epidemiol Biomarkers Prev 16:731-739

22. Adesanya OO, Zhou J, Samathanam C, Powell-Braxton L, Bondy CA (1999) Insulin-like growth factor 1 is required for G2 progression in the estradiol-induced mitotic cycle. Proc Natl Acad Sci USA 96:3287-3291

23. Holmes MD, Murin S, Chen WY, Kroenke CH, Spiegelman D, Colditz GA (2007) Smoking and survival after breast cancer diagnosis. Int J Cancer 120:2672-2677

24. Fentiman IS, Allen DS, Hamed H (2005) Smoking and prognosis in women with breast cancer. Int J Clin Pract 59:1051-1054

25. Sagiv SK, Gaudet MM, Eng SM et al (2007) Active and passive cigarette smoke and breast cancer survival. Ann Epidemiol 17:385-393

26. Manjer J, Andersson I, Berglund G et al (2000) Survival of women with breast cancer in relation to smoking. Eur J Surg $166: 852-858$

27. Sopori M (2002) Effects of cigarette smoke on the immune system. Nat Rev Immunol 2:372-377

28. Kendall A, Folkerd EJ, Dowsett M (2007) Influences on circulating oestrogens in postmenopausal women: relationship with breast cancer. J Steroid Biochem Mol Biol 103:99-109

29. Terry PD, Rohan TE, Franceschi S, Weiderpass E (2002) Cigarette smoking and the risk of endometrial cancer. Lancet Oncol 3:470-480

30. Carmichael AR (2006) Obesity and prognosis of breast cancer. Obes Rev 7:333-340

31. Chlebowski RT (1994) Dietary fat intake reduction for patients with resected breast cancer. Adv Exp Med Biol 364:11-23

32. Chlebowski RT, Aiello E, McTiernan A (2002) Weight loss in breast cancer patient management. J Clin Oncol 20:1128-1143

33. Kroenke CH, Chen WY, Rosner B, Holmes MD (2005) Weight, weight gain, and survival after breast cancer diagnosis. J Clin Oncol 23:1370-1378

34. Caan BJ, Emond JA, Natarajan L et al (2006) Post-diagnosis weight gain and breast cancer recurrence in women with early stage breast cancer. Breast Cancer Res Treat 99:47-57

35. Byers T, Sedjo RL (2006) A weight loss trial for breast cancer recurrence: pre-menopausal, post-menopausal, both, or neither? Cancer Causes Control 17:1-3

36. McTiernan A, Rajan KB, Tworoger SS et al (2003) Adiposity and sex hormones in postmenopausal breast cancer survivors. J Clin Oncol 21:1961-1966

37. Griggs JJ, Sorbero ME, Lyman GH (2005) Undertreatment of obese women receiving breast cancer chemotherapy. Arch Intern Med 165:1267-1273

38. Carmichael AR, Bates T (2004) Obesity and breast cancer: a review of the literature. Breast 13:85-92

39. Dignam JJ, Wieand K, Johnson KA, Fisher B, Xu L, Mamounas EP (2003) Obesity, tamoxifen use, and outcomes in women with estrogen receptor-positive early-stage breast cancer. J Natl Cancer Inst 95:1467-1476

40. Messina M, Caskill-Stevens W, Lampe JW (2006) Addressing the soy and breast cancer relationship: review, commentary, and workshop proceedings. J Natl Cancer Inst 98:1275-1284

41. Boyapati SM, Shu XO, Ruan ZX et al (2005) Soyfood intake and breast cancer survival: a followup of the Shanghai Breast Cancer Study. Breast Cancer Res Treat 92:11-17

42. Limer JL, Speirs V (2004) Phyto-oestrogens and breast cancer chemoprevention. Breast Cancer Res 6:119-127

43. Wu AH, Pike MC, Williams LD et al (2007) Tamoxifen, soy, and lifestyle factors in Asian American women with breast cancer. J Clin Oncol 25:3024-3030 
44. von SE, Rutqvist LE (2005) Menopausal hormone therapy after breast cancer: the Stockholm randomized trial. J Natl Cancer Inst 97:533-535

45. Holmberg L, Anderson H (2004) HABITS (hormonal replacement therapy after breast cancer-is it safe?), a randomised comparison: trial stopped. Lancet 363:453-455

46. Holm LE, Nordevang E, Hjalmar ML, Lidbrink E, Callmer E, Nilsson B (1993) Treatment failure and dietary habits in women with breast cancer. J Natl Cancer Inst 85:32-36

47. Zhang S, Folsom AR, Sellers TA, Kushi LH, Potter JD (1995) Better breast cancer survival for postmenopausal women who are less overweight and eat less fat. The Iowa Women's Health Study. Cancer 76:275-283

48. McEligot AJ, Largent J, Ziogas A, Peel D, Anton-Culver H (2006) Dietary fat, fiber, vegetable, and micronutrients are associated with overall survival in postmenopausal women diagnosed with breast cancer. Nutr Cancer 55:132-140

49. Hebert JR, Hurley TG, Ma Y (1998) The effect of dietary exposures on recurrence and mortality in early stage breast cancer. Breast Cancer Res Treat 51:17-28

50. Saxe GA, Rock CL, Wicha MS, Schottenfeld D (1999) Diet and risk for breast cancer recurrence and survival. Breast Cancer Res Treat 53:241-253

51. Rohan TE, Hiller JE, McMichael AJ (1993) Dietary factors and survival from breast cancer. Nutr Cancer 20:167-177

52. Chlebowski RT, Blackburn GL, Thomson CA et al (2006) Dietary fat reduction and breast cancer outcome: interim efficacy results from the Women's Intervention Nutrition Study. J Natl Cancer Inst 98:1767-1776

53. Holmes MD, Stampfer MJ, Colditz GA, Rosner B, Hunter DJ, Willett WC (1999) Dietary factors and the survival of women with breast carcinoma. Cancer 86:826-835

54. Kyogoku S, Hirohata T, Nomura Y, Shigematsu T, Takeshita S, Hirohata I (1992) Diet and prognosis of breast cancer. Nutr Cancer 17:271-277

55. Wynder EL, Taioli E, Rose DP (1992) Breast cancer-the optimal diet. Adv Exp Med Biol 322:143-153

56. Rock CL, Flatt SW, Thomson CA et al (2004) Effects of a highfiber, low-fat diet intervention on serum concentrations of reproductive steroid hormones in women with a history of breast cancer. J Clin Oncol 22:2379-2387

57. Kroenke CH, Fung TT, Hu FB, Holmes MD (2005) Dietary patterns and survival after breast cancer diagnosis. J Clin Oncol 23:9295-9303

58. Pierce JP, Natarajan L, Caan BJ et al (2007) Influence of a diet very high in vegetables, fruit, and fiber and low in fat on prognosis following treatment for breast cancer: the Women's Healthy Eating and Living (WHEL) randomized trial. JAMA 298: 289-298

59. Ingram D (1994) Diet and subsequent survival in women with breast cancer. Br J Cancer 69:592-595

60. Fleischauer AT, Simonsen N, Arab L (2003) Antioxidant supplements and risk of breast cancer recurrence and breast cancer-related mortality among postmenopausal women. Nutr Cancer 46:15-22

61. Rock CL, Flatt SW, Natarajan L et al (2005) Plasma carotenoids and recurrence-free survival in women with a history of breast cancer. J Clin Oncol 23:6631-6638

62. Goodwin PJ, Ennis M, Pritchard KI, Koo J, Trudeau ME, Hood N (2003) Diet and breast cancer: evidence that extremes in diet are associated with poor survival. J Clin Oncol 21:2500-2507

63. Veronesi U, Mariani L, Decensi A et al (2006) Fifteen-year results of a randomized phase III trial of fenretinide to prevent second breast cancer. Ann Oncol 17:1065-1071

64. Ladas EJ, Jacobson JS, Kennedy DD, Teel K, Fleischauer A, Kelly KM (2004) Antioxidants and cancer therapy: a systematic review. J Clin Oncol 22:517-528

65. D'Andrea GM (2005) Use of antioxidants during chemotherapy and radiotherapy should be avoided. CA Cancer J Clin 55: 319-321

66. McDonald PA, Williams R, Dawkins F, Adams-Campbell LL (2002) Breast cancer survival in African American women: is alcohol consumption a prognostic indicator? Cancer Causes Control 13:543-549

67. Tapiero H, Townsend DM, Tew KD (2004) The role of carotenoids in the prevention of human pathologies. Biomed Pharmacother 58:100-110

68. Rock CL, Kusluski RA, Galvez MM, Ethier SP (1995) Carotenoids induce morphological changes in human mammary epithelial cell cultures. Nutr Cancer 23:319-333

69. Boffetta P, Hashibe M (2006) Alcohol and cancer. Lancet Oncol 7:149-156

70. Ballard-Barbash R, McTiernan A (2007) Is the whole larger than the sum of the parts? The promise of combining physical activity and diet to improve cancer outcomes. J Clin Oncol 25:2335-2337

71. Jones LW, Demark-Wahnefried W (2006) Diet, exercise, and complementary therapies after primary treatment for cancer. Lancet Oncol 7:1017-1026

72. Doyle C, Kushi LH, Byers T et al (2006) Nutrition and physical activity during and after cancer treatment: an American Cancer Society guide for informed choices. CA Cancer J Clin 56: 323-353

73. Demark-Wahnefried W, Clipp EC, Lipkus IM et al (2007) Main outcomes of the FRESH START trial: a sequentially tailored, diet and exercise mailed print intervention among breast and prostate cancer survivors. J Clin Oncol 25:2709-2718

74. Sabatino SA, Coates RJ, Uhler RJ, Pollack LA, Alley LG, Zauderer LJ (2007) Provider counseling about health behaviors among cancer survivors in the United States. J Clin Oncol 25:2100-2106

75. Wold KS, Byers T, Crane LA, Ahnen D (2005) What do cancer survivors believe causes cancer? (United States). Cancer Causes Control 16:115-V23

76. Irwin ML (2006) Randomized controlled trials of physical activity and breast cancer prevention. Exerc Sport Sci Rev 34:182-193 